\title{
Symposium on Amartya Sen's Philosophy: 3 Sen and Consequentialism
}

\section{Citation}

Scanlon, Thomas M. 2001. Symposium on Amartya Sen's philosophy: 3 Sen and consequentialism. Economics and Philosophy 17, no.1: 39-50.

\section{Published Version}

http://dx.doi.org/10.1017/S026626710100013X

\section{Permanent link}

http://nrs.harvard.edu/urn-3:HUL.InstRepos:3228652

\section{Terms of Use}

This article was downloaded from Harvard University's DASH repository, and is made available under the terms and conditions applicable to Other Posted Material, as set forth at http:// nrs.harvard.edu/urn-3:HUL.InstRepos:dash.current.terms-of-use\#LAA

\section{Share Your Story}

The Harvard community has made this article openly available.

Please share how this access benefits you. Submit a story.

Accessibility 


\title{
SYMPOSIUM ON AMARTYA SEN'S PHILOSOPHY: 3 SEN AND CONSEQUENTIALISM
}

\author{
T. M. SCANLON \\ Harvard University
}

It is a particular pleasure to be able to participate in this symposium in honor of Amartya Sen. We agree on a wide range of topics, but I will focus here on an area of relative disagreement. Sen is much more attracted to consequentialism than I am, and the main topic of my paper will be the particular version of consequentialism that he has articulated and the reasons why he is drawn to this view.

Let me begin by distinguishing two forms of consequentialism. What I will call Foundational Consequentialism starts with some notion of value and explains notions such as right, wrong, rights, duty and obligation in terms of the production of the best states of affairs as measured by this standard. By contrast, Representational Consequentialism starts with widely shared intuitions about right and wrong, and shows how a conception of value can be constructed so that these intuitions can be squared with the thesis that an act is right if and only if it is productive of the best consequences.

The motivation for these is quite different, as is their likely content. The explanatory and justificatory aims of Foundational Consequentialism provide strong reason for keeping its conception of value free of deontic notions such as rights and duties, since this form of the view arises from the idea that these notions are in need of explanation and justification. This form of consequentialism might be taken to start from the belief that the idea of 'the good' has clearer and more obvious justificatory force than 'the right'. The idea is that even before any particular notion of the good is specified, it is obvious that we have strong reason to promote the good, but that, by contrast, it is unclear why we should be concerned not to violate principles of rightness, especially insofar as this requires something different from promoting 
the good and can even conflict with it. Something like this is often maintained, I believe, but it is unclear to me at least why it should be thought true. Perhaps it seems true because 'good' is understood in a 'buck-passing' sense (Scanlon 1998, pp. 95-100) as 'whatever we have reason to promote', whereas 'rightness' is presented in the form of certain specific requirements considered in abstraction from any explanation of why they should be reason-giving.

However this may be, I believe that the case for Foundational Consequentialism is stronger when it is not based on this abstract idea of the good but rather on some specific notion of value that seems to have distinctive normative force. Thus, although consequentialism is nowadays often presented in an abstract form, leaving the notion of the good unspecified (as in Kagan, 1989, p. 60), I believe that it is utilitarianism that exhibits most clearly the appeal of the Foundational version of the view.

As Sen says, utilitarianism can be seen as the conjunction of three theses: (1) consequentialism, according to which the rightness of actions depends on the value of the states of affairs they produce; (2) welfarism, according to which the value of a state of affairs is a function of the welfare of individuals; and (3) sum-ranking, according to which this function is additive. Although these theses are logically independent, it seems to me that their appeal is not independent, and that in fact it is welfarism (or, historically, hedonism) that provides the support for the other two. Although hedonism does not entail sum-ranking, it is plausible that if pleasure and the absence of pain is the sole ultimate value, then since more of it is better than less, the value of states of affairs should be determined by the amount of happiness they contain.

More important for present purposes is the relation between hedonism and consequentialism. If pleasure and the absence of pain are the sole ultimate values (or the only morally relevant ultimate values), then all (moral) value adheres in states of affairs, and what morality requires is that we produce those states of affairs with the greatest possible value. It is, of course, a further question whether these states of affairs are to be thought of as including actions, which may contribute to their value, or whether actions should be held to have no value in themselves and can be morally significant only insofar as they produce something of value. Sen refers to the latter position as involving 'an arbitrary exclusion' (Sen, 1982, p. 29). He writes, 'Had welfarism not been additionally imposed, consequentialism could have coexisted with taking note of such things as the values and disvalues of actions through the valuation of the states, which include these actions' (Sen, 1985, p. 182).

There are, however, two factors at work here, which should be distinguished. The first is that a particular conception of value, according 
to which actions in themselves have no value, can support an interpretation of 'state of affairs' which excludes actions and includes only their valuable consequences. If pleasure and pain are understood simply as particular kinds of sensations or experiences then hedonism has this consequence, since actions in themselves will have no value apart from the experiences they produce. But this is not the most plausible form of hedonism. In a more plausible form, happiness and even pleasure have to be understood in a way that includes taking pleasure in doing things and recognizes that the good that is at issue in such cases involves the activity essentially, not simply as a means of producing an experience or sensation of pleasure. ${ }^{1} \mathrm{~A}$ similar point holds in the case of Welfarism. If welfare is understood simply as a state that actions can produce, then Welfarism may seem to exclude actions as determinants of value. But if welfare is a matter of preference satisfaction, and people have preferences about which actions they perform, then Welfarism can recognize that actions can be valuable - can contribute to the value of states of affairs of which they are a part - in the same sense in which anything else, such as particular experiences, can.

But, whether actions can have value or not, and whether they therefore should or should not be taken into account in determining the value of states of affairs, the aims of Foundational Consequentialism dictate that at least the deontic values of actions - their rightness or wrongness, whether or not they violate rights and so on - should not be included as determinants of the value of states of affairs. This is the second factor I mentioned above. It is one thing to include, as a determinant of the value of a state of affairs, the fact that it includes an action that an agent would much prefer not to have performed; but it is something else again to take into account the fact that this action was wrong, or violated someone's right.

Sen observes that 'Some ethical theories (like utilitarian ethics) insist ... that nonutility features, such as actions, must not be considered to be of any value or disvalue on their own (rather, only for the utilities or disutilities that they generate). But since there are good reasons to be concerned about some of these features, such as actions, motives, and the like (for reasons that are close enough to those which move deontologists, among others, to take note of them, in their own special way) the utilitarian exclusion ends up being an arbitrary exclusion of a class of reasoned demands' (Sen, 2000, pp. 487-88).

Restricting the evaluation of states of affairs in this way may be a mistake, and it may be unfair for critics of consequentialism to insist on

${ }^{1}$ Here I correct an oversimplification in my earlier presentation of these ideas (Scanlon 1998, pp. 100-101). The point is made clearly by Bernard Williams. (Smart and Williams, 1973, pp. 84-5). 
attacking this less plausible, welfarist version of the doctrine. But the restriction may also reflect certain assumptions which, although they may be mistaken, do not seem arbitrary. These are, first, that the consequentialism in question, utilitarianism, is a version of Foundational Consequentialism; second, that the values of such things as actions and their motivational bases could only be moral values; and, third, that including these in the valuation of states of affairs would therefore be in conflict with the explanatory aims of the doctrine.

Sen departs from the narrowest model of consequentialism in a way that involves rejecting these assumptions. He includes actions as parts of the states of affairs that are to be evaluated, and he believes that part of this evaluation should take into account whether they involve people's rights being violated. This indicates, I believe, that what he is drawn to is not Foundational Consequentialism but rather a version of Representational Consequentialism. This brings us to the question of why one should find this doctrine appealing. Why should it be an advantage to represent rights, duties and other deontic notions in terms of the value of outcomes, even if in so doing one does not explain them in terms of an independent and allegedly clearer notion of value?

One class of reasons that might be offered for this are what I will call reconciliationist. If one accepts the maximization of the value of outcomes as a formal standard of rationality, then deontological constraints will seem problematic if the form of practical reasoning that they involve cannot be fitted within this framework. Showing that these values can be adequately represented in terms of the values of states of affairs would lay this objection to rest. More substantively, if one is attracted by the idea that one should always act 'for the best', then one might be troubled by the fact that deontological constraints may sometimes require one to act in ways that do not fit with this appealing axiom. It would allay this objection if one could show that, substantively, the most satisfactory understanding of what 'the best' involves is one that removes this apparent tension.

It is possible that Sen is moved by one of these aims. At least, I believe that his reasons for being attracted to consequentialism are like these (and different from some other possible sources of the view) in flowing from a point of view that takes common sense morality, including its apparently deontological components, seriously and seeks to defend it. But his main reasons are, I believe, more straightforwardly substantive and positive than the reconciliationist ones I have just listed. He believes, I think, that quite apart from any need to reconcile common sense morality with other demands, the best interpretation of familiar moral notions themselves involves, at least in part, their inclusion as factors that contribute to the value of states of affairs. In particular, he believes that the best interpretation of rights involves this. 
Sen's first argument for this is based on the following example (Sen, 1982, pp. 7-19). Donna has discovered that a group of racists ('the bashers') plan to ambush and beat Ali at an isolated spot where he is going. In order to warn him, she must learn his destination, which she can only do by breaking into the room of Charles, a friend of Ali's who greatly values his privacy. Sen stipulates that, taking into account the distress that this would cause Charles and the pleasure that the group of bashers will get from beating up Ali, overall preference satisfaction would be maximized by Donna's not breaking into Charles's room and thus allowing the beating to occur. Nor would a view based on strict deontological constraints permit the break in, he says, since it would violate an important right of Charles's. Nonetheless, Sen believes that it would be permissible for Donna to break into Charles's room in order to warn Ali. The best way to explain this fact, he believes, is to take account of the very significant negative value of a state of affairs in which Ali's right not to be beaten is violated, and hence the positive value of preventing this state of affairs from occurring. He concludes that the kind of view that can best account for this case is what he calls a goalrights system - one in which the value of states of affairs takes into account the value of protecting rights and the disvalue of having them violated.

It is, however, open to question whether an explanation of the case along these lines really needs to appeal to the idea that Ali has a right not to be beaten up. Given the stipulations Sen has made, it is clear that it would not be sufficient to appeal merely to considerations of welfare, understood as preference satisfaction. But there is quite a lot of space between preference satisfaction on the one hand and the idea of a right on the other. In this intermediate space, we might appeal simply to the idea that it is a very bad thing for Ali if he is beaten, and that the pleasure that the bashers will get from beating him is not of comparable moral significance, even if there are a great number of them and they will each enjoy it very much.

It might be claimed that the preference-independent moral significance appealed to here just amounts to a right. But is this so? As Sen himself goes on to point out, the case does not depend on the fact that some agent or agents (the bashers) will inflict the injury on Ali. We could as well assume that Donna has learned that there is an unexploded bomb near where Ali is going, and that she needs to break into Charles's room to get the telephone number where she can reach Ali to warn him. So the right in question, if it is one, is not a right against other agents, that they not harm him, but a right not to be deprived of certain 'functionings'. But again, why do we need to call this a right? We do need to say that it is morally important to protect Ali against this injury. But many things are morally important without being rights. 
Perhaps the idea is that something that could justify violating Charles's right of privacy would have to be a right, since only a right can 'trump' another right. But this does not seem to me to be the best way of looking at the matter. First, it does not seem true that only a right can justify interfering with or abridging another right. Property rights, for example, can be infringed when this is necessary for important public purposes, even thought there is no right to the benefits involved, and I believe that something similar is true of most rights, including rights to privacy. Second, I do not think that the best way to understand these cases, in which two rights appear to be in conflict, is to suppose that rights have a certain moral 'weights' and that what we are doing is deciding whether one right is or is not 'outweighed' by another (or by some other competing consideration.) Rather, it seems to me that rights, as we commonly understand them, have certain exceptions built into them, and that it does not in general take another right to trigger these exceptions. What we are doing in many 'conflict' situations, I would suggest, is not balancing rights off against one another but asking whether one of these rights (the one that we are tempted to 'violate') is or is not best understood as allowing for an exception in cases of the kind in question. (If the answer is 'yes', then we are not, properly speaking, violating the right even though we may be doing what it would normally forbid.) $)^{2}$

To spell this out, consider an instrumental theory of rights, which Sen considers at several points and sets aside (for example, in Sen, 1982, p. 15) without, however, rejecting it. According to an instrumental account, to claim that people have a certain right is to claim that they have some important interest that can be adequately protected only if others' freedom to act is constrained in certain ways. For example, people have good reason to want to be able to count on having the use of and certain forms of control over objects, and to be able to conduct parts of their lives free from the scrutiny of strangers. So they need, and can reasonably insist on, rights which constrain the freedom of others to take their possessions, or to pry into their affairs. But we also recognize that absolute prohibitions against interfering in these ways would be unacceptably costly to others. So, in order to be defensible, rights have to be understood as admitting of exceptions. In deciding whether a defensible right would have to incorporate a certain exception, we must take into account not only the relative seriousness of the interests in question (the interest that the right is meant to protect and the interest that would be sacrificed without the exception) but also the degree to

2 In Judith Thomson's helpful terminology (Thomson, 1990, p. 122), the right is infringed but not violated. 
which the secure protection that the right is meant to provide would be undermined by an exception of the kind in question.

I am suggesting, then, that in cases like those in which Sen suggests we must consider rights as goals, what we are actually taking as 'to be promoted' are the underlying interests which rights protect, and in terms of which they are justified. But we are at the same time, I believe, considering these interests within the framework of the right understood as a constraint - a limitation on our freedom to act - that is justified in the instrumental way just described. We are asking whether the instrumental rationale embodied in the right does or does not admit of an exception in cases like the one at hand. So, for example, in the case of Donna, Charles, and Ali, the question is whether someone in Ali's position could reasonably reject a version of the right to privacy that would not permit Donna to break into Charles's room if this were the only way to prevent Ali from being seriously injured. Ali's interest in not suffering this injury figures in this analysis not as a right but as a consideration that goes into determining the structure of Charles's right.

I have so far been examining one reason that Sen advances for including actions in general, and right-violating actions in particular, as components of states of affairs in a consequentialist (or consequencesensitive) theory. A second reason he sees for doing this is that a system of moral thinking that has this form has the morally appealing property of requiring agents to take responsibility for their actions (and the consequences of these actions) in the proper way. He illustrates this (Sen, 2000, pp. 480ff.) with an episode from the Mahabharata in which Arjuna, on the eve of a great battle against the forces of a usurper, bemoans the fact that in the coming battle, although his cause is just and victory is likely, multitudes will be killed, and he himself will have to kill many, including people of whom he is very fond. Arjuna wonders whether it is worth it, whether it would not be better to let the usurpers take over without a battle. Against this, Krishna urges the 'deontological' position that since Arjuna's cause is just it is his duty to fight, 'whatever the consequences'.

Sen finds Arjuna's reluctance morally more appealing than the harsher deontology defended by Krishna. He takes this case to illustrate two important points. First, that a morally adequate assessment of a state of affairs must take into account the actions that it involves (Arjuna is right to care about the fact that he will be killing these people.) Second, that states of affairs have different values when evaluated from different 'positions' (the fact that Arjuna himself will have killed people he is fond of makes the coming state of affairs worse when judged from his position as agent than it would be when judged from the point of view of a neutral third party, who would have reason to regard the deaths as a bad thing, but would not him or herself be involved in bringing them about). 
In this particular case, including actions as part of the states of affairs to be evaluated and conducting this evaluation in a 'position-relative' way appears to favor Arjuna's more 'consequentialist' position over Krishna's 'deontological' one. But in other cases, Sen believes that these features of his consequence-sensitive view enable it to account for much, if not all, of what anti-consequentialists such as Nagel and Williams want to insist on under the heading of 'agent-relative reasons'.

Merely attaching an agent-neutral negative value to the occurrence of states of affairs involving rights violations would not achieve this result. For (assuming sum-ranking) one would then always be required to commit a right-violating act, no matter how heinous, if doing so were the only way to prevent several similar right-violations from being committed by others. This would not even be a dilemma on such a view; it would be obvious what one should do.

Position-relative evaluation takes us farther than this. Just as Arjuna is right to attach special negative value to the prospect of his having to kill many people, so Jim, in Williams's well-known example, ${ }^{3}$ would be correct to attach special negative value to his killing one of the villagers. In order to justify Jim's refusing the role offered to him, the special negative value attached to killing would have to be very great, and Sen seems to me to leave it open whether it could be taken to be this large. But the position-relative view at least allows us to see why this case presents a dilemma. Indeed, it would seem that position-relative agent values might come in on both sides of the case, thus heightening the dilemma. Jim needs to take into account not only the disvalue of his killing one of the villagers but also, I would think, the disvalue of his less direct involvement in the deaths of all ten villagers if he refuses. This seems to be part of what it is for him to 'take responsibility for the consequences of his actions'. To simply say that the deaths of these others was not his doing would be to side too firmly with Krishna.

This account is appealing, but I nonetheless want to raise a few questions about it. ${ }^{4}$ First, as Sen points out, attaching a position-relative

3 Utilitarianism: For and Against, pp. 98-9.

${ }^{4}$ In passages of mine that Sen quotes (Sen, 2000, pp. 498-91) I was making the point that one cannot account for the intuitive wrongness of killing by attaching an agent-neutral disvalue to the occurrence of such acts. In addition to the problem, mentioned above, that on such a view it would be simply obvious that one should kill one to prevent several killings by others, there is the further problem that the reason one person has not to kill is not identical with the reason that anyone has to prevent a killing. On this, Sen and I agree, and I also agree with him that deontological prohibitions do not exhaust the morality of right and wrong (my point was just that an adequate theory should account for those cases in which these prohibitions seem correct). Our disagreement is about whether the best account of such cases is one based simply on position-relative evaluations of states of affairs. In the remainder of this paper I explain why I believe that the best account is not of this form. 
disvalue to rights-violating actions does not fully capture the kind of constraints that deontologists have in mind. This seems clear to me intuitively, but is more difficult to establish through plausible examples. One kind of case that might bring out the non-equivalence would be a situation in which you have set in motion some train of causes that will kill five people unless you manage to prevent it from running its course, but you can only do this by killing another person (Kamm, 1996, pp. 239-43). Suppose, for example, that you have set a bomb, which will kill five if it goes off. You then have second thoughts, but in order to defuse the bomb in time you would have to kill another person, who is in the way. Doing so would violate a deontological constraint against killing, as this is normally understood. But it is not ruled out by a position-relative disvalue of the kind that Sen proposes. In order to defuse the bomb, you must bring about a state of affairs in which you have killed an innocent person. But if you do not do this, then you will have brought about a state of affairs in which you will have killed five. The disvalue of the latter state of affairs, evaluated from your position as agent, is surely at least as great as that of the former.

One might, of course, conclude that the intuition expressed in the deontological constraint is mistaken, and that it is permissible to kill the one in such a case. But the proposed analysis also has a further implication that seems implausible. This is that it is permissible to kill the one in such a case because otherwise you will have killed the five, and that this would not be permissible (or would be less clearly permissible) if someone else had set the bomb and you were the only person in a position to defuse it. This seems mistaken: the fact that it was you who set the bomb may mean that you have a special responsibility to defuse it if you can, but it does not seem to affect the permissibility of your killing an innocent person in order to do so. ${ }^{5}$

There is also another worry about this appeal to the idea of positionrelative disvalue. It is sometimes charged that people who, faced with a choice like Jim's in Williams's example, refuse to kill for the sake of some much greater good, are 'keeping their hands clean' or 'preserving their own moral purity' at the expense of others. This charge seems to be strengthened by the suggestion that the reason someone in this position has to refuse to kill is the special disvalue, from his or her position, of a state of affairs in which he or she will have killed someone. To fend off this objection, one might stress that the idea that a state of affairs has special disvalue when evaluated from a particular position should not be identified with the idea that it is bad for the person in that position. But what, then, does this special disvalue come to? If it consists simply in the

${ }^{5}$ Kamm also mentions this point and the following one about 'keeping your hands clean' (Kamm, 1996, p. 243). 
fact that a person in that position has a special (non-self-interested) reason not to bring it about, then this begins to look more like a moral prohibition, albeit one that is not absolute.

Moreover, the charge of 'preserving one's moral purity' brings out another way in which it seems, intuitively, mistaken to explain the wrongness of killing by appealing to the agent's objection to being a killer. In the cases in which it seems clearest that it would be wrong to kill one to save five, the wrongness of doing this seems to arise most basically from a special claim of the victim, not to be killed. The problem that these cases raise is how to reconcile this claim with the claims of others to be saved. Insofar as the agent has a special reason not to kill in such a case, this reason seems to derive from a resolution of this problem rather than to be the factor that provides this resolution.

This does not mean, however, that position-relative reasons are not real, or that they lack moral significance. Arjuna is right to regret not only that many people he is fond of will be killed in the coming battle but also, especially, that he will be the one who does much of the killing. Any reasonably sensitive person would feel the same way. The reason in question does not depend on any thought that what he will do will be wrong - he has reason to feel this way even if what he does will be morally permissible, and even his duty. His reasons for regret derive not from conceptions of right and wrong, but from the significance for his relations with these people and their relatives, of his being the agent of their harm.

On a contractualist view, position-relative reasons of this kind have their most basic moral significance as factors that help to shape the principles by which actions are judged. For example, because of the special significance for an agent of being the direct cause of harm to a friend or family member, or even of failing to save them, it would be reasonable to reject principles that required us to be strictly neutral between friends or family members and strangers - for example, by requiring one to flip a coin to decide between saving a friend and saving a stranger. Position-relative values of the kind Sen identifies thus explain why acceptable principles must incorporate what Scheffler called agentcentered prerogatives.

In presenting this analysis, as in my earlier discussion of an instrumental account of rights, I have slipped into a two-level form of moral argument, consisting of one level at which actions are judged right or wrong according to principles and another, more fundamental level, at which these principles in turn are justified. (By contrast, the consequentialism Sen discusses seems mostly to be of the 'direct' variety, in which actions are justified by direct appeal to their consequences.) But how are principles to be justified in a two-level view? It may seem that at this more fundamental level we are all consequentialists, or at least that I am one. 
Any acceptable process through which principles of action are justified must at least be consequence-sensitive, to use Sen's term. It must at least take consequences into account. If we go further with Sen and insist, plausibly, that the grounds for evaluating consequences must not be limited to individual welfare, but can include other things that individuals have reason to care about, then what can be relevant in the assessment of a principle other than the consequences for individuals of its being generally adopted? I believe that the point of divergence here between contractualism and consequentialism concerns not just what is relevant but how it is taken into account.

Consequentialism, as I understand it, holds that, whatever view we take of the overall goodness of states of affairs, we should employ that notion of goodness as the ultimate basis for assessing actions: we should perform the actions that would produce the best states of affairs, judged by this standard (or, in a two-level view, the actions allowed by those principles whose general observance would have such consequences). By contrast, as a contractualist, I hold that in deciding which principles should govern our actions we should consider not the overall value of resulting states of affairs but the reasons that individuals have for accepting or rejecting these principles. This means, first, that we consider only the ways in which these principles would affect individuals, not their impact on the realization of impersonal values; and second, that we need to compare the distinctive reasons that individuals in different positions have for objecting to a principle. These reasons will, as I have just suggested above, be position-relative. For example, the reasons that someone has to object to a principle from the position of an agent who will be bound by it will not in general be the same as those that someone has from the position of a victim, or an affected bystander.

Contractualism thus naturally employs position-relative reasons, but does not require position-relative evaluations of overall states of the world. This enables it to avoid a prima-facie problem that arises for a position-relative consequentialist theory. If the consequentialist idea of acting for the best is to provide a single standard of right action, it seems to require a single idea of what is best as its evaluative basis. There is thus a puzzle about how to formulate consequentialism on the basis of multiple, position-relative evaluative standpoints. Perhaps it becomes the view that what morality requires is for each person to act for the best, as judged from his or her position. I will leave open the question of how this is to be worked out. My point is that within a contractualist view the problem does not arise. Contractualism does not require a single standard of overall evaluation. What it requires is, rather, an account of what various individuals, in virtue of their diverse positions, have reason to want, and a way of comparing these reasons - not by deciding what is best overall but by comparing the importance of a particular 
benefit from one position with the importance of a burden from some other position.

So, whether position-relative evaluation can be incorporated within a consequentialist theory or not, and whether or not it provides what is needed to make such a theory fit more easily with common sense morality, position-relative reasons have an important to role to play in a contractualist theory. By taking them into account, such a theory can accommodate a number of the points that Sen's discussion of positionrelativity calls to our attention.

\section{REFERENCES}

Kagan, Shelly. 1998. The Limits of Morality. Oxford University Press

Kamm, Frances. 1996 Morality, Mortality, Vol. II. Oxford University Press

Scanlon, T. M. 1998 What We Owe to Each Other. Harvard University Press

Sen, Amartya. 1982. 'Rights and agency'. Philosophy \& Public Affairs, 11:3-39

Sen, Amartya. 1985. 'Well-being, agency and freedom: the Dewey Lectures 1984'. The Journal of Philosophy, 82:169-221

Sen, Amartya. 2000. 'Consequential evaluation and practical reason'. The Journal of Philosophy, 96:477-502

Smart, J. J. C., and Bernard Williams. 1973. Utilitarianism: For and Against. Cambridge University Press

Thomson, Judith. 1990. The Realm of Rights. Harvard University Press 